\title{
Extent of centrilobular and panacinar emphysema in smokers' lungs: pathological and mechanical implications
}

\author{
M. Saetta*, W.D. Kim, J.L. Izquierdo ${ }^{\dagger}$, H. Ghezzo†, M.G. Cosio
}

Extent of centrilobular and panacinar emphysema in smokers' lungs: pathological and mechanical implications. M. Saetta, W.D. Kim, J.L. Izquierdo, H. Ghezzo, M.G. Cosio. CERS Journals Ltd 1994.

ABSTRACT: In order to quantify the extent of centrilobular (CLE) and panacinar (PLE) emphysema and the degree of the possible overlap between the two forms in smokers, the lungs of 25 smokers undergoing lung resection for peripheral lung tumours were studied.

The extent of CLE and PLE was assessed by point counting, and the lungs were classified as having pure CLE $(C, n=5)$, predominant CLE with areas of PLE (CP, $n=7)$, predominant PLE with features of CLE (PC, $n=7)$, and pure PLE $(P, n=6)$ according to the percentage of lung involved by either form. Preoperative pulmonary function tests and the score of inflammation and the diameters of the small airways were also measured.

Mean linear intercept $(\mathbf{L m})$, a measure of mean interalveolar wall distances and forced expiratory volume in one second $\left(\mathrm{FEV}_{1}\right)$ were similar in the four groups. Small airway pathology was a predominant feature in lungs with CLE, and was significantly decreased in a stepwise fashion as the amount of PLE increased. This was especially so for the amount of muscle in the airway wall and the diameters of the airways. By contrast, lung compliance was higher in panacinar than in centrilobular emphysema.

We conclude that: 1) smokers may reach similar values of airflow obstruction and parenchymal destruction in two completely different ways, developing either centrilobular or panacinar emphysema; 2) these two types of emphysema may be present in pure form or may overlap each other, but one type is always clearly predominant; and 3) the degree of either form has important consequences on the degree of airway abnormality and on the mechanical properties of the lung. Eur Respir J., 1994; 7: 664-671.
${ }^{\dagger}$ Respiratory Division, Royal Victoria Hospital, and Meakins Christie Laboratories, McGill University, Montreal, Quebec, Canada. *Instituto di Medicina del Lavoro, Universita' di Padova, Padova, Italy.

Correspondence: M.G. Cosio

Respiratory Division

Room L4.11

Royal Victoria Hospital 687 Pine Avenue West

Montreal

Quebec

Canada H3A $1 \mathrm{~A} 1$

\section{Keywords:}

Chronic obstructive pulmonary disease emphysema smokers bronchiolitis

Received: May 251993

Accepted after revision January 171994
Emphysema is defined as "permanent enlargement of the air spaces distal to the terminal bronchiole associated with destruction of their walls and without obvious fibrosis" [1]. Such emphysematous lesions, as assessed macroscopically, may involve, homogeneously, the secondary lobules from centre to periphery (panacinar emphysema), or may be localized in the centre of secondary lobules and surrounded by normal alveoli (centrilobular emphysema).

Cigarette smoking is a major risk factor in the development of pulmonary emphysema, and it has been classically associated with the centrilobular form of emphysema [2]. Recently, EIDELMAN et al. [3] found two different patterns of functional abnormalities in smokers: some exhibited pressure-volume curves typical of emphysema, with high compliance and low elastic pressures at high volumes. On the other hand, about half of their subjects had low or normal compliance, and pressure-volume curves that were unlike those described as typical of emphysema. Subsequently, KIM et al. [4] showed two different microscopic patterns of lung destruction corresponding to these functional abnormalities, and concluded that smokers can develop either centrilobular (CLE) or panlobular (PLE) emphysema. By simply examining microscopic sections, either CLE or PLE appeared to be predominant in smokers lungs, but in some cases, features of the two types of emphysema were seen in the same lung.

The purpose of this study was to assess precisely the extent of lung involvement by CLE and PLE and the degree of the possible overlap between the two forms of emphysema in smokers lungs. Also, we wanted to examine the effects of either emphysema and their possible combinations on the pathological abnormalities of the airways and lung physiology. To this end, we morphometrically quantitated the amount of lung involvement with each kind of emphysema by point counting, and compared the results with the morphometric evaluation of airway pathology and physiological measurements.

\section{Methods}

Lungs or lobes were obtained from 25 patients who had been admitted to the hospital for surgical resection of small peripheral non-obstructing pulmonary nodules. 
Lungs showing any evidence of pneumonitis or loss of volume upon pathological examination were excluded. All patients were males and had smoked for at least 35 yrs. None had a history of asthma or any occupational exposure to dust or noxious chemicals. All subjects had pulmonary function tests performed within 3 weeks before surgery. Informed consent was obtained from all patients.

\section{Pulmonary function tests}

Pulmonary function tests (PFT) were performed according to the standard protocol of the National Institutes of Health [5]. The PFT included measurements of forced expiratory volume in one second $\left(\mathrm{FEV}_{1}\right)$ and forced vital capacity (FVC), which were performed using a Wedge spirometer and were corrected for body temperatures and pressure saturated with water vapour (BTPS). All values were expressed as percentage predicted, using the formula of Morris et al. [6]. The lung volume subdivisions of residual volume (RV), functional residual capacity (FRC), and total lung capacity (TLC) were measured in a volume displacement, pressure compensated, body plethysmograph and expressed as percentage predicted, using the prediction formulae of GoldMAN and BeCKLAKE [7]. Pressure-volume curves of the lung were obtained using the oesophageal balloon technique [8] as described previously $[3,9]$. Static compliance $(\mathrm{Cst}=0.5 l$ divided by pressure changes between FRC and FRC +0.5 l), and specific compliance $(\mathrm{Csp}=\mathrm{Cst} \div \mathrm{FRC})$ were obtained. All pressure-volume points were fitted to the exponential equation $\mathrm{V}=\mathrm{A}-\mathrm{Be}^{-\mathrm{KP}}$ using an iterative least-square method [10]. Transpulmonary pressure at $90 \%$ of measured TLC $\left(\mathrm{PL}_{90}\right)$ and $\mathrm{K}$, which is an index of lung distensibility, were computed and expressed as percentage predicted, using the predicted equations of COLEBATCH et al. [11].

\section{Morphology}

Upon resection, lungs or lobes were fixed by intrabronchial infusion of $10 \%$ formalin, with the pressure maintained at $25 \mathrm{cmH}_{2} \mathrm{O}$ for at least $24 \mathrm{~h}$. Sagittal slices of the lung, $1 \mathrm{~cm}$ thick, were cut and randomly selected template tissue blocks, $2.5 \times 2 \mathrm{~cm}$, were taken from the sagittal slice away from the tumour site, i.e. six for a lobe and 10 for a lung. Sections $6 \mu$ thick were stained with periodic acid Schiff and haematoxylin, phloxine, saffron (PAS-HPS) for light microscopy [12]. All sections were randomized by one researcher, who did not know the history of the subjects. This code was not broken until all morphometric assessments had been completed. Only sections that were determined to be free of cutting artifacts were accepted for use, i.e. free of compression caused by cutting, tearing etc. If any section was found to have a tumour it was not used for the analysis.

\section{Emphysema point counting}

Point counting was performed using a light microscope with $\mathrm{a} \times 2.5$ objective and $\mathrm{a} \times 10$ eyepiece. The latter contained a graticule with 42 points that were at the centre of hairline crosses (Weibel No. 2; Graticules, Tonbridge, Kent, UK). Areas under these points (alveolar or duct spaces) were classified as normal $(\mathrm{N})$, centrilobular (CLE) or panacinar (PLE) spaces. In normal lung, the diameter of alveoli around the acinus constitutes about a quarter to a third of the outer diameter of the alveolar duct [13]. In PLE, the distinction between alveoli and alveolar ducts tends to become lost as alveoli lose their sharp angles, enlarge and then lose their contrast in size and shape with alveolar ducts. Therefore, we considered an alveolus enlarged when its diameter was larger than a third of the outer diameter of the alveolar ducts in the same secondary lobule. An area was considered to have PLE when secondary lobules were homogeneously affected by enlargement of alveoli and alveolar ducts from centre to periphery, although not every lobule had to be involved [14] (fig. 1b). Focal enlargement of alveoli was not regarded as evidence of PLE. At least two thirds of the microscopic field around the point had to be involved with PLE to be counted as such.

An area was considered to have CLE when sharply demarcated emphysematous spaces surrounded by normal alveoli and alveolar ducts were observed [15] (fig. 1a).

a

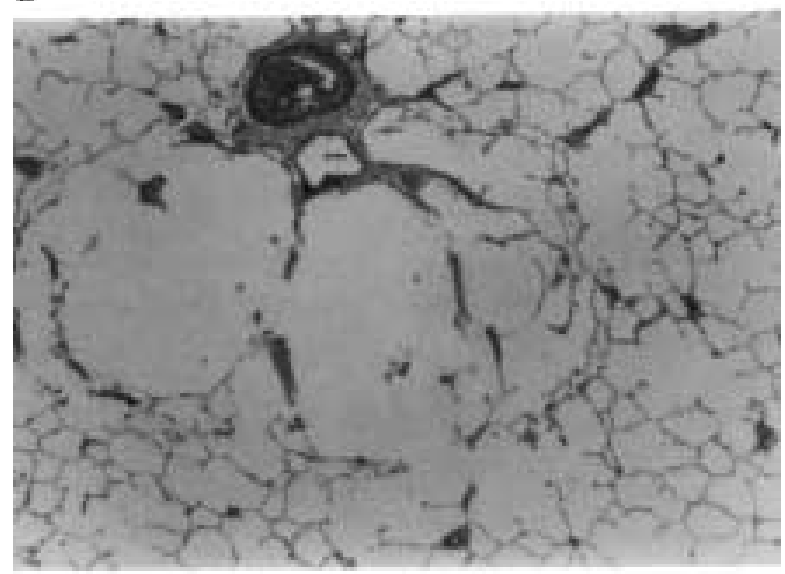

b

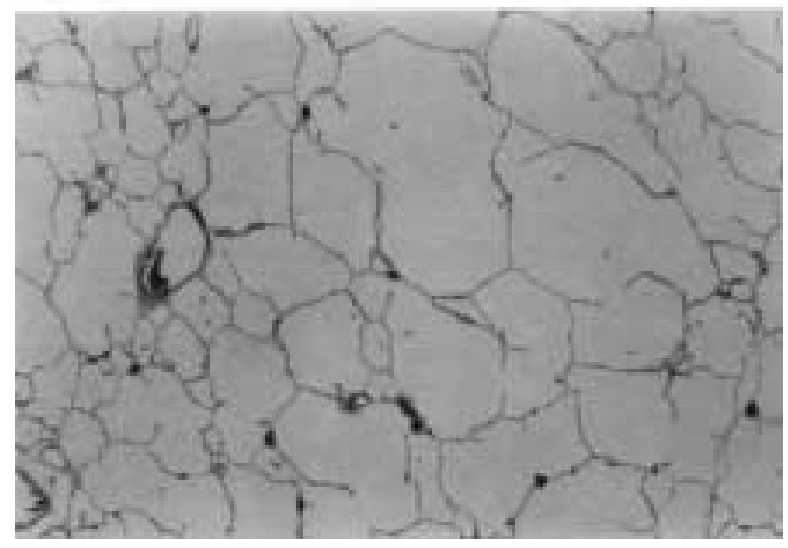

Fig. 1. - Photomicrographs showing: a) Centrilobular emphysema (CLE); and b) panacinar emphysema (PLE). See text for explanation. (Magnification $\times 25$ ). 
The inflammatory and fibrotic component in the wall of emphysematous spaces was regarded as an important clue for the diagnosis of CLE [15]. Sometimes, clear areas of PLE showed inflammation and fibrosis in the wall of the emphysematous spaces. We identified these areas as having "features of CLE" (fCLE), counted them as fCLE and differentiated them from pure CLE, because they were not surrounded by normal alveoli.

The air spaces directly under the cross hair points were counted as N, CLE, PLE or fCLE according to the previous definitions. Ten to fifteen fields per slide were examined and three indices were calculated: 1) \%CLE= CLE points/total points $\times 100 ;$ 2) \%PLE=PLE points/total points $\times 100$; 3) $\%$ fCLE $=$ fCLE points/total points $\times 100$; and 4) \%EMPH=total emphysematous points (\%CLE+ \%PLE+\%fCLE). Points falling over other structures, such as vessels or bronchioles did not enter into the calculations. For each subject, the final value for each index is the average of all the slides of that subject. Isolated dilatation of otherwise normal alveolar ducts (duct ectasia), a feature of the ageing lung, was carefully differentiated from PLE and counted as normal lung.

In order to diagnose CLE, there is a need for identification of normal alveolar structure surrounding emphysematous spaces. We have thus estimated that the largest possible score for CLE is around 60\%: the graticule we used has 42 points; if three external sides of the graticule (17 points) fall over normal areas, the maximum possible score for centrilobular emphysema per field is (42-17)/ $42 \times 100=59.5 \%$. Beyond this score, emphysema could be quantified but not identified, since in this case there would not be enough surrounding area of normal tissue necessary for the definition of CLE.

All slides were evaluated by a single observer who did not have access to the code. In order to test the reproducibility of the measurements, 10 slides were randomly selected for reading by a second observer and by the main observer three months later. Both the intraobserver and the interobserver reproducibility were acceptable ( $r=0.90$; $\mathrm{p}<0.001$; and $\mathrm{r}=0.83 ; \mathrm{p}<0.005$, respectively).

\section{Coefficient of variation (CV) of interalveolar wall distance and mean linear intercept $(\mathrm{Lm})$}

Measurement of interalveolar wall distance was made using a microscope with a $\times 10$ objective and $\times 10$ eyepiece, using the modified method of THURLBECK [16]. Interalveolar wall distances were measured in at least 20 fields for each slide, using a single hairline rotated through $90^{\circ}$ (10 fields in each direction), so that at least 100 fields were measured for each lung or lobe. Using the values obtained in each field, the standard deviation and the CV (standard deviation/mean) of interalveolar wall distances were calculated as measures of distribution dispersion, in an attempt to define the evenness or unevenness of the destruction. Mean interalveolar wall distances as a whole for each lung or lobe were expressed as a mean linear intercept $(\mathrm{Lm})$ of the lung or lobe. The size of the section was determined by digitizing its area, and Thurlbeck's formula for correction of Lm for tissue shrinkage was used to obtain the final value of $\mathrm{Lm}$ [16].

\section{Small airway pathology}

The pathology of the small airways was quantified, using the method described by Cosio and co-workers [17, 18], by a different investigator to the one assessing emphysema point counting. Each bronchiole $2 \mathrm{~mm}$ and less in diameter was examined separately for the presence of five different pathological changes. These abnormalities included: goblet cell metaplasia in the epithelium, and inflammatory cell infiltrate, fibrosis, smooth muscle hypertrophy, and pigment deposits in the airway wall. For each airway, a score from 0 (normal) to $3+$ (most abnormal) was assigned for each pathological feature. Scores for individual features were summed and expressed as a percentage of the maximal possible score for each lung. The total pathological score for small airways is simply the sum of the score for all five individual abnormalities.

The internal diameter of each non-respiratory bronchiole was measured using a calibrated graticule in the eyepiece. Luminal diameters were measured from basement membrane to basement membrane as the maximum distance perpendicular to the long axis of the airway lumen, and were corrected for shrinkage [18]. The percentage of airway less than $400 \mu$ in internal diameter was then computed [18].

\section{Data analysis}

Results are expressed as means \pm standard deviations. Differences in means between groups were assessed with analysis of variance and Tucky-Kramer multiple comparison test. A two-tailed probability of 0.05 was considered a significant difference.

\section{Results}

The average age of the 25 subjects studied was $65 \pm 6$ yrs and they had a smoking history of $67.3 \pm 22.1$ packs per year (table 1). The results of pulmonary function tests are shown in table 1.

Table 1. - Physiological data of the 25 subjects examined

\begin{tabular}{lcc}
\hline & Range & Mean \pm sD \\
\hline Age yrs & & $65 \pm 6$ \\
Smoking packs $\cdot \mathrm{yrs}^{-1}$ & & $67.31 \pm 22.1$ \\
$\mathrm{FEV}_{1} \%$ pred & $53-116$ & $80 \pm 15$ \\
$\mathrm{PL}_{90} \%$ pred & $43-128$ & $83 \pm 24$ \\
$\mathrm{~K} \%$ pred & $63-200$ & $113 \pm 147$ \\
$\mathrm{Csp} \mathrm{cmH} \mathrm{O}^{-1}$ & $0.034-0.199$ & $0.080 \pm 0.040$ \\
$\mathrm{Cst} l \cdot \mathrm{cmH}_{2} \mathrm{O}^{-1}$ & $0.128-0.775$ & $0.326 \pm 0.144$ \\
\hline
\end{tabular}

$\mathrm{FEV}_{1}$ : forced expiratory volume in one second; $\mathrm{PL}_{90}$ : elastic recoil pressure at $90 \%$ of total lung capacity; $\mathrm{K}$ : exponential constant describing the whole pressure-volume curve; Csp: specific compliance; Cst: static compliance. 


\section{Morphometric data}

The results of point counting for emphysema are shown in figure 2, where the CLE score that combines \%CLE+ $\%$ fCLE is plotted against the corresponding PLE score (\%PLE) in the 25 cases studied. As already explained (see Methods), the CLE axis is cut at the value of $60 \%$, and the "identify line" meaning "equivalence line", joins the origin with the point where PLE $=100 \%$ and $\mathrm{CLE}=60 \%$. From this figure, it appears that two main groups can be clearly separated, one with a predominant panacinar and the other with a predominant centrilobular type of emphysema. Among each main group (centrilobular and panacinar), two further subgroups can be identified, a subgroup with a "pure" type of emphysema $(\mathrm{C}=$ pure centrilobular, with less than $10 \%$ panacinar and $\mathrm{P}=$ pure panacinar, with less than $10 \%$ centrilobular, along the margins of figure 1) and a subgroup with a "mixed" type of emphysema $(\mathrm{CP}=$ prevalent centrilobular with $10 \%$ or more panacinar, $\mathrm{PC}=$ prevalent panacinar with $10 \%$ or more centrilobular features in this case). Table 2 shows the results of the point counting in the four subgroups of emphysema, C, CP, PC and P. From this table, it can be seen that, even in the mixed forms (CP and $\mathrm{PC})$, there is always a clearly predominant type of emphysema. Furthermore, it should be noticed that the PC lungs are partially panacinar lungs $(\% \mathrm{PLE}=59)$ with some inflammation in the alveolar walls $(\% \mathrm{fCLE}=17)$, whilst the classical centrilobular lesions (CLE) contribute only $1 \%$ of counts.

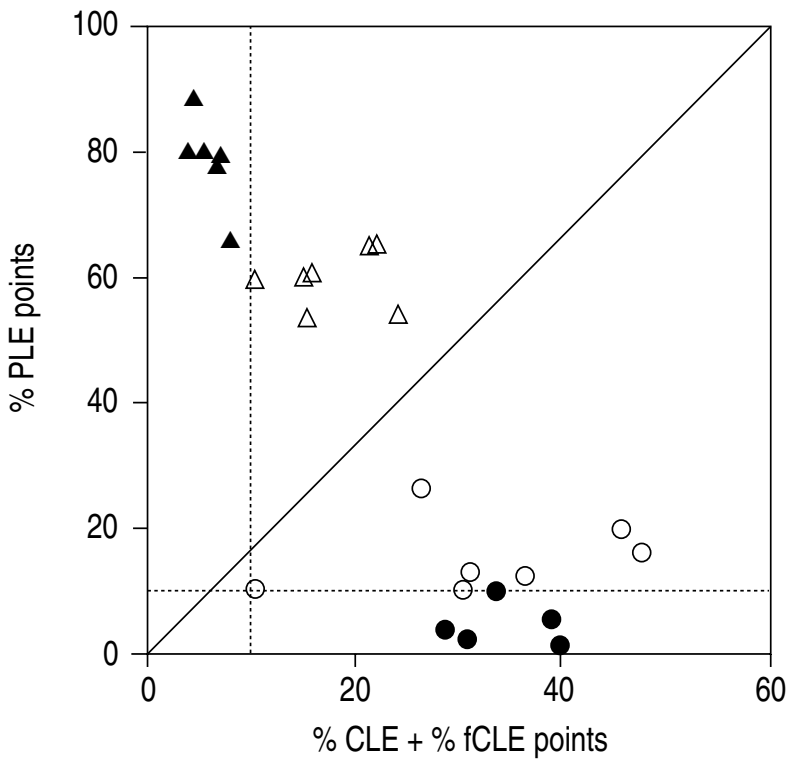

Fig. 2. - Individual values of emphysema point counting in the 25 smokers studied. For each case, the centrilobular points (\% CLE + \% fCLE) are plotted against the panacinar points (\% PLE). Each symbol represents one subject. The continuous line is the "line of equivalence" which separates the two main groups (centrilobular emphysema (CLE) and panacinar emphysema (PLE), and the dotted lines indicate the range below $10 \%$, which allows each main group to be separated into two subgroups (pure centrilobular $(\mathrm{C})(\bullet)$ and mixed with predominant centrilobular (CP) (O) for CLE; and mixed with predominant panacinar $(\mathrm{PC})(\Delta)$ and pure panacinar $(\mathrm{P})(\boldsymbol{\Delta})$ for PLE. fCLE: features of CLE. See text for detailed definitions.
Table 2. - Results of point counting for emphysema in 25 smokers divided into four groups

\begin{tabular}{lcccc}
\hline & $\mathrm{C}$ & $\mathrm{CP}$ & $\mathrm{PC}$ & $\mathrm{P}$ \\
\hline Cases $\mathrm{n}$ & 5 & 7 & 7 & 6 \\
\% CLE & $34 \pm 6$ & $32 \pm 5$ & $1 \pm 1$ & $0.1 \pm 0.1$ \\
\% fCLE & $0.1 \pm 0.1$ & $0.4 \pm 0.2$ & $17 \pm 2$ & $6 \pm 1$ \\
\% PLE & $5 \pm 1$ & $16 \pm 2$ & $59 \pm 2$ & $79 \pm 3$
\end{tabular}

C: pure centrilobular; CP: mixed, with predominant centrilobular; PC: mixed, with predominant panacinar; P: pure panacinar; CLE: centrilobular emphysema; fCLE: features of CLE; PLE: panacinar emphysema. For definition of point see text.

There was no difference in $\mathrm{Lm}$ and destructive index (DI) among groups, whilst CV significantly decreased in a stepwise fashion from $\mathrm{C}$ to $\mathrm{P}(\mathrm{F}=2.58 ; \mathrm{p}<0.05)$.

Figure 3 compares the airway abnormalities in the four groups of emphysema. The total score significantly decreased in a stepwise fashion from $\mathrm{C}$ to $\mathrm{P}(\mathrm{F}=8 ; \mathrm{p}<0.001)$. The total airway diameter increases significantly from $0.435 \pm 0.09$ in $\mathrm{C}$ to $0.652 \pm 0.08$ in $\mathrm{P}(\mathrm{F}=3.56 ; \mathrm{p}<0.05)$. The lower diameters in the $\mathrm{C}$ groups were due to a larger proportion in airways less than $400 \mu$ in diameter, that decreased significantly towards $\mathrm{P}(\mathrm{F}=5.84 ; \mathrm{p}<0.004)$.

Figure 4 shows the score obtained for all the inflammatory components of the small airways and their trends in the different emphysema type. Muscle $(\mathrm{F}=8.89$; $\mathrm{p}=0.0001)$, fibrosis $(\mathrm{F}=6.06 ; \mathrm{p}<0.004)$, and cellular inflammatory infiltrates $(\mathrm{F}=6.38 ; \mathrm{p}<0.003)$ are highest in $\mathrm{C}$ and significantly decreased in a stepwise fashion with the lower values in P. No significant differences in goblet cells and pigment deposition were seen.

When all the cases were pooled together, the total score for airway abnormalities had a significant negative correlation with the mean internal airway diameter $(r=$ -0.386; $\mathrm{p}<0.02$ ) (not shown) and a positive correlation with the percentage of airways less than $400 \mu \mathrm{m}$ in diameter $(r=0.556 ; p<0.01)$ (fig. 5a). When the emphysema groups were separated into $\mathrm{C}(\mathrm{C}$ and $\mathrm{CP})$ versus $\mathrm{P}(\mathrm{PC}$ and $\mathrm{P}$ ) total score correlated with airway size only in the $\mathrm{P}$ emphysemas $(\mathrm{r}=0.633 ; \mathrm{p}<0.003)$, and not in $\mathrm{C}$ emphysemas $(\mathrm{r}=0.241 ; \mathrm{p}=\mathrm{NS})$.

Among the components of the total score, muscle score was the only abnormality significantly correlated with the internal airway diameter $(\mathrm{r}=0.472 ; \mathrm{p}<0.004)$, and with the percentage of airways less than $400 \mu$ in diameter $(\mathrm{r}=0.616 ; \mathrm{p}<0.005)$ (fig. 5b). Muscle score was correlated with percentage airways less than $400 \mu$ in diameter both in $\mathrm{P}$ emphysemas $(\mathrm{r}=0.495 ; \mathrm{p}<0.03)$ and in $\mathrm{C}$ emphysemas $(\mathrm{r}=0.450 ; \mathrm{p}<0.05)$.

The airway inflammatory infiltrate was correlated with the extent of lung destruction as measured by DI in the $\mathrm{C}$ emphysemas $(\mathrm{r}=0.617 ; \mathrm{p}<0.02$ (fig. $6 \mathrm{a}$ ), but not in the $\mathrm{P}$ emphysemas ( $\mathrm{r}=-0.009 ; \mathrm{p}>0.05$ ) (fig. $6 \mathrm{~b}$ ).

\section{Physiological data}

The $\mathrm{FEV}_{1}$ and $\mathrm{PL}_{90}$ were similar in the four groups. Lung compliance expressed as either $\mathrm{Cst}(\mathrm{F}=4.76 ; \mathrm{p}<0.01)$ 
a)

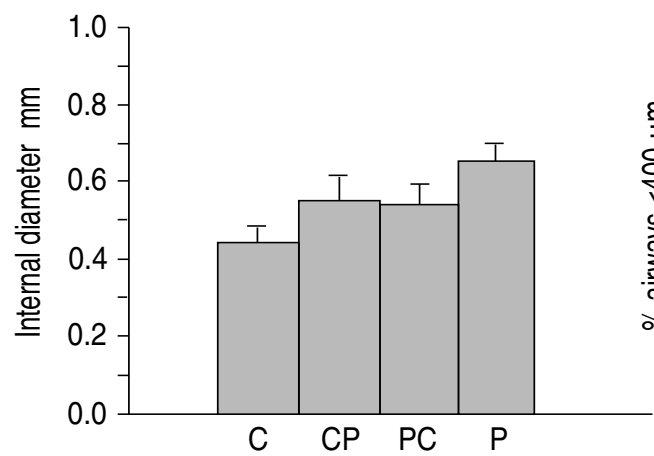

b)

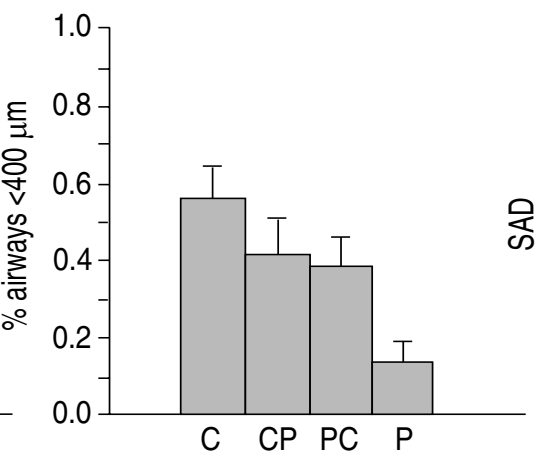

c)

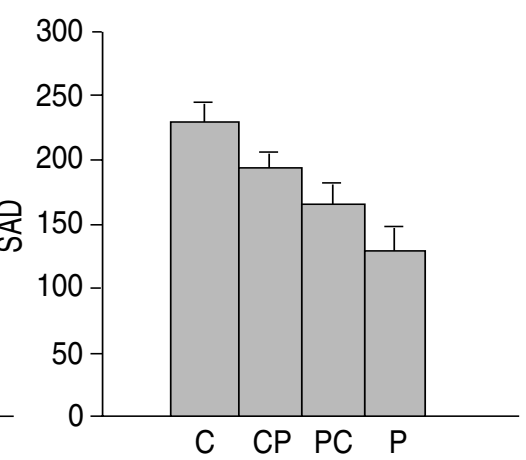

Fig. 3. - Values for: a) internal airway diameter; b) the percentage of airways smaller than 400 um in diameter; and c) the score of airway abnormalities (SAD) in the four emphysema groups. Significant differences were found by analysis of variance (ANOVA) in the three parameters $(\mathrm{F}=3.56 ; \mathrm{p}<0.05) ;(\mathrm{F}=5.84 ; \mathrm{p}<0.0001) ;(\mathrm{F}=8 ; \mathrm{p}<0.0001)$, respectively. Bars represent means and standard errors. C: pure centrilobular; $\mathrm{CP}$ : mixed with predominant centrilobular; PC: mixed with predominant panacinar; P: pure panacinar.

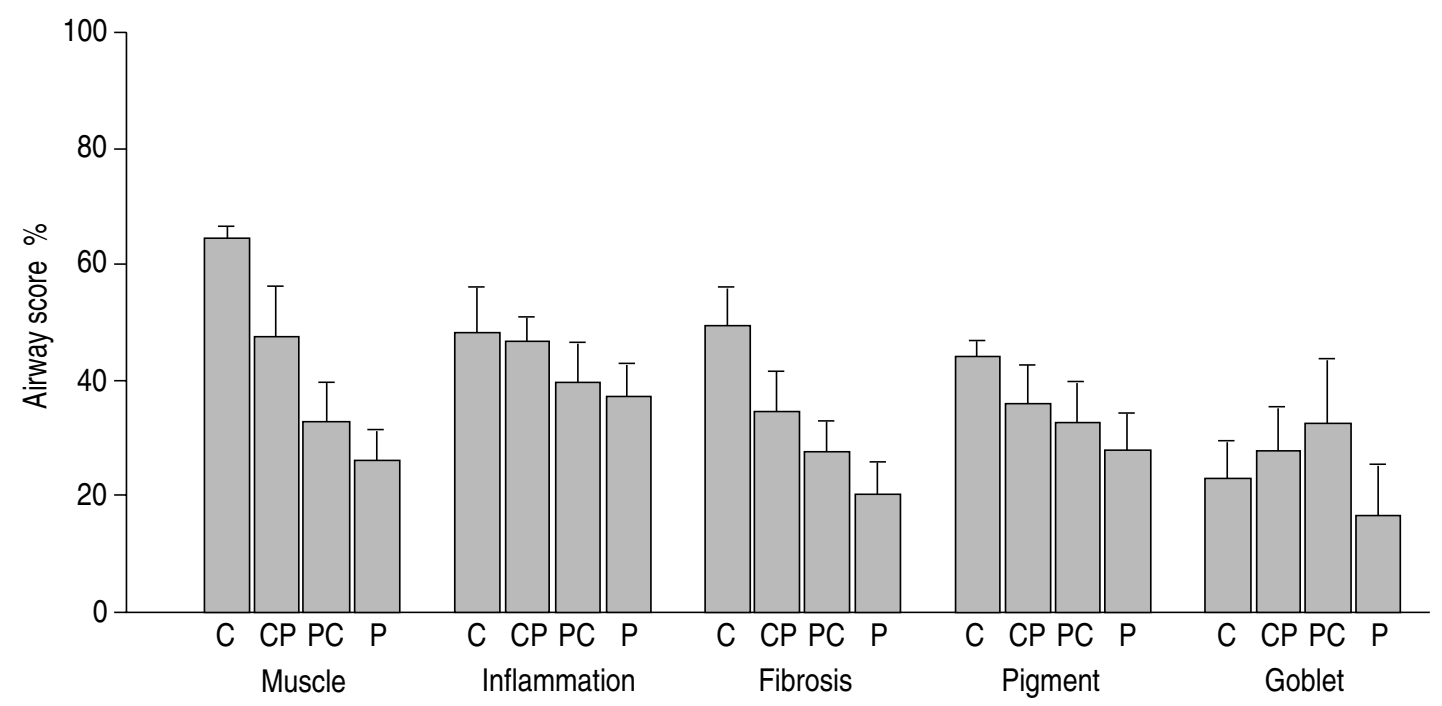

Fig. 4. - Values of the five components of the airway score in the 25 smokers divided into four emphysema groups (C, CP, PC and P). A significant decrease from $\mathrm{C}$ to $\mathrm{P}$ was found in the amount of muscle $(\mathrm{F}=8.89 ; \mathrm{p}=0.0001)$, fibrosis $(\mathrm{F}=6.60 ; \mathrm{p}<0.004)$; and inflammation ( $\mathrm{F}=6.38$; $\mathrm{p}<0.003)$ by analysis of variance (ANOVA). Bars represent means and standard errors. For definitions see legend to figure 3.

a)

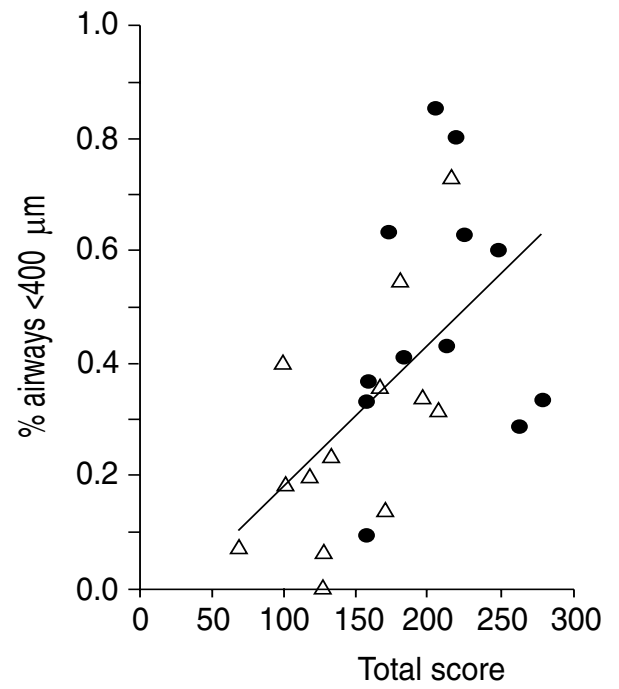

b)

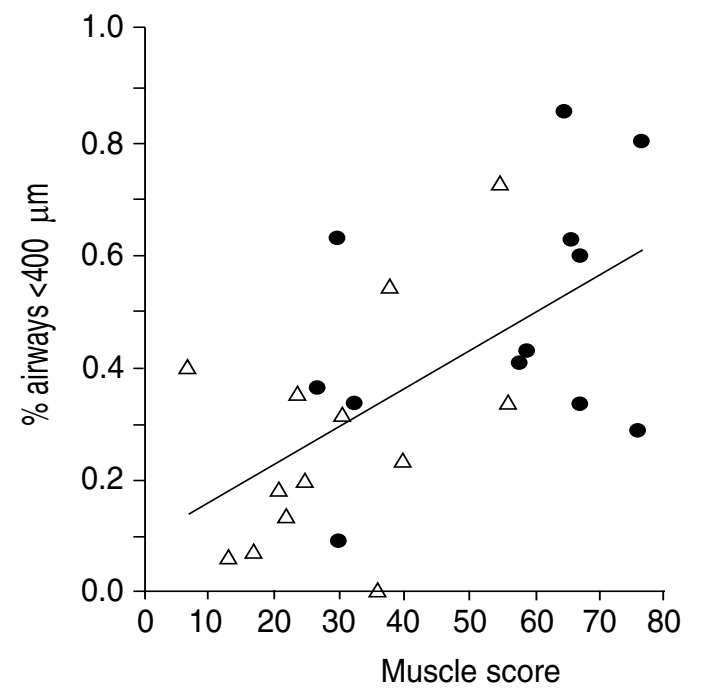

Fig. 5. - a) Correlations between the total score of airways abnormalities and the proportion of airways less than $400 \mu \mathrm{m}$ in diameter in cases with CLE $(\mathrm{C}+\mathrm{CP})(\bullet)$ and PLE $(\mathrm{P}+\mathrm{PC})(\Delta)(\mathrm{r}=0.556 ; \mathrm{p}<0.01)$. b) Correlation between the muscle score and the proportion of airways less than $400 \mu \mathrm{m}$ in diameter in the same groups as in $(\mathrm{a}) ; \mathrm{r}=0.616 ; \mathrm{p}<0.005$. For abbreviations see legend to figures 2 and 3 . 
a)

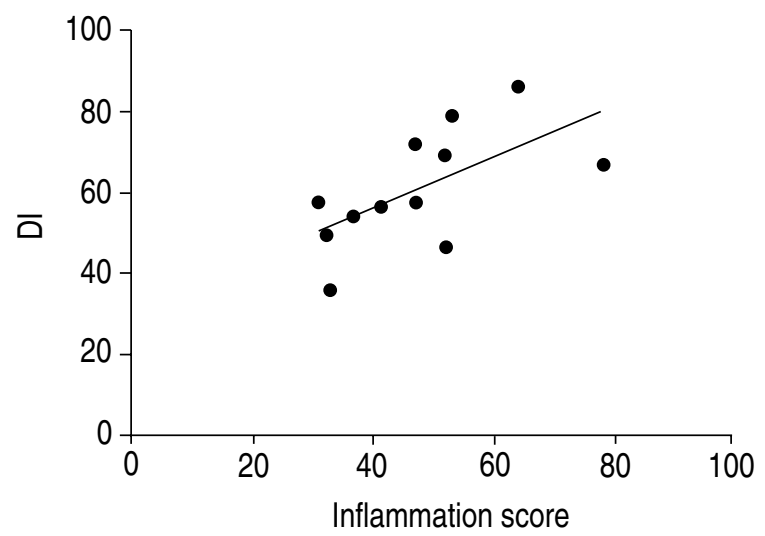

b)

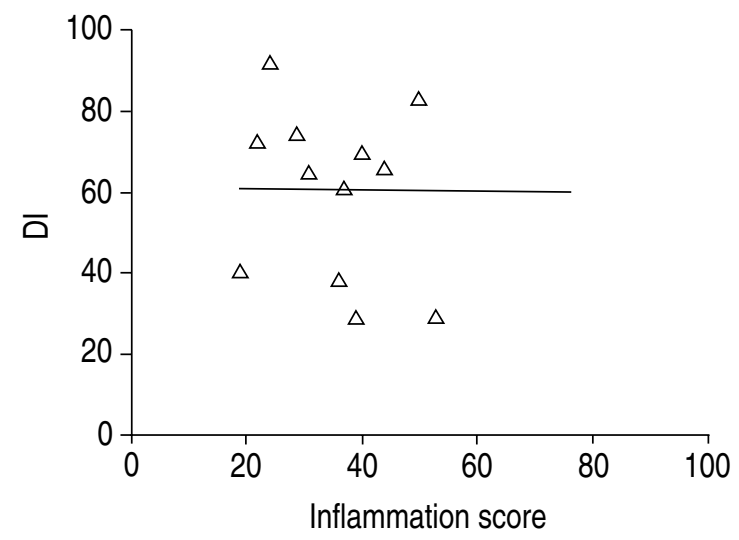

Fig. 6. - Correlation between the inflammation score in the small airways and the destructive index (DI): a) in CLE; and b) in PLE. A significant correlation is present in CLE ( $r=0.617$; $<<0.025)$ but not in PLE ( $r=-0.009 ; \mathrm{p}=\mathrm{Ns}$ ). Ns: nonsignificant. For further abbreviations see legend to figure 2 .

or $\operatorname{Csp}(\mathrm{F}=5.76 ; \mathrm{p}<0.005)$ increased significantly from $\mathrm{C}$ to $\mathrm{P}$, and $\mathrm{K}$ showed a worsening trend from $\mathrm{C}$ to $\mathrm{P}$ but did not reach statistical significance $(\mathrm{F}=2.32 ; \mathrm{p}<0.103)$.

\section{Discussion}

In previous work, KIM et al. [4] found that two different morphological patterns of lung destruction, centrilobular and panacinar emphysema, can be identified by simply observing microscopic sections in smokers lungs. In the present study, we have extended the observations of KIM et al. [4] by precisely assessing, using point counting, the extent of lung involvement by either type of emphysema in smokers. We found that centrilobular and panlobular emphysema can be present in pure form or may overlap each other and that, even in the mixed forms, one type of emphysema is always clearly predominant. The type of emphysema present has important consequences on the degree of airway abnormalities and on the mechanical properties of the lung.

The point counting method described here is not intended to be a new way to quantitate emphysema microscopically for the purpose of comparing morphology and function. Since panlobular emphysema is an evenly distributed disease, whilst centrilobular emphysema is an uneven focal disease, they involve, by definition, a large and a low percentage of the lung, respectively. For example, as pointed out by THURLBECK and co-workers [19], if $25 \%$ of the lung is involved with mild panacinar emphysema, a score of $25 \%$ would result, whereas in centrilobular emphysema every respiratory bronchiole might be enlarged and destroyed, in order to get a similar score. Thus, for the same score, centrilobular lesions are proportionally more severe than panlobular lesions. In spite of these limitations, this method was a good tool for the purpose of the present study, i.e. to differentiate and accurately quantitate the different types of emphysema in smokers' lungs. Based on this method, we classified the lungs of our population of smokers as: $\mathrm{C}=$ pure centrilobular; $\mathrm{CP}=$ predominant centrilobular with areas of panlobular; $\mathrm{PC}=$ predominant panlobular with "features" of centrilobular; and $\mathrm{P}=$ pure panlobular.
The extent of involvement of the lung parenchyma with emphysema, as assessed by the mean linear (Lm) alveolar size or by the destructive index (DI), was similar in all the emphysemas. However, as assessed by the coefficient of variation (CV) of Lm [4] this destruction was very uneven in $\mathrm{C}$ lungs, and became more even as $\mathrm{P}$ became predominant.

We divided the lungs into four types of emphysema to study carefully the possible overlap of the two types of lung destruction. Although our findings do suggest that some of the CLE characteristics can, at times, be seen in PLE and vice versa, this finding might have more importance from the point of view of pathogenesis of lung destruction than functional significance. Examining table 2, it can be seen that the majority of emphysema points are CLE in CP lungs and that the majority of emphysema points are PLE in PC lungs. For this reason, we found that it was justifiable, at times, to group together the $\mathrm{C}$ emphysemas $(\mathrm{C}+\mathrm{CP})$ and the $\mathrm{P}$ emphysemas $(\mathrm{P}+\mathrm{PC})$ in the analysis of our data.

The differences in the quantity and quality of airway involvement in the four emphysema groups are quite striking. The total score of airway abnormalities is highest in pure $\mathrm{C}$ lungs and decreases, in a stepwise fashion, to the lowest value in pure $\mathrm{P}$ lungs. This pattern could be seen for all the components of the airway inflammatory reaction, except for the goblet cells and pigment, suggesting that pure CLE is characterized by severe involvement of the small airways, with a striking increase in the amount of muscle. When CLE is found to have areas of PLE the airway abnormalities seem to decrease, and when PLE is mixed with CLE the airway abnormalities seem to increase. Probably as a consequence of the degree of airway abnormalities the size of airways is smallest in CLE and largest in PLE. Similarly, as the emphysemas tend to mix the size of the airways become more similar. Thus, it seems that smokers develop a marked chronic inflammatory reaction in the small airways, with all the classical components of inflammation present, i.e. cells, fibrosis and muscle. However, for the same age and smoking history $\mathrm{C}$ emphysemas have a more prominent reaction with more cells, muscle and fibrosis in their walls. The pathological abnormalities in the 
small airways seem to account for the size of the airways, as suggested by correlations found between total score and either mean diameter or the percentage of airways less than $400 \mu$ in diameter. However, total score correlated with airway calibre in panlobular emphysemas $(\mathrm{P}+\mathrm{PC})$ but not in centrilobular emphysemas $(\mathrm{C}+\mathrm{CP})$, and when the components of the total score were compared individually with diameters, only the amount of muscle in the airway wall was correlated with airway calibre in centrilobular emphysema. These data suggest that the inflammatory process in PLE, upon encroaching on the airway wall, decreases airway diameters. By contrast, in CLE, the inflammatory process probably induces muscles constriction that reduces airway size even further. Since this feature cannot be quantitated by morphology, the measurement of airway size is not correlated with the overall disease in the small airways but only with the amount of muscle.

It has been postulated that increased airway reactivity is an important pathogenic mechanism in the development of chronic obstructive pulmonary disease (COPD) in smokers [20]. However, available data are controversial and do not support this hypothesis, mainly because reactivity is strongly related to the baseline $\mathrm{FEV}_{1}$. Our data, showing that two populations of smokers exist, invite speculation that increased airway reactivity could indeed be an important pathogenic mechanism in smokers with centrilobular emphysema, where increased cellular infiltrate, amount of muscle, and increased proportion of narrowed airways are a more prominent feature for the same degree of lung destruction. By contrast, in smokers with panlobular emphysema, normal airway reactivity could be found, and the mechanism for the disease would probably not include airway involvement as a primary event.

We have shown in this study that two main differences can be found between CLE and PLE: the extent of involvement of the airways and the pattern of parenchymal destruction. It could then be speculated that the uneven type of lung destruction (high CV) found in CLE represents areas of emphysematous destruction around the airways, related to the inflammation in these airways and surrounded by normal alveoli distant to airways. In the evenly distributed PLE (low CV) the destruction is diffuse and there would be no relationship to airway inflammation. In favour of this hypothesis is the correlation found between the airways cellular inflammatory infiltrate and lung destruction (DI) in CLE but not in PLE, despite a similar range of DI and inflammation score in the two groups. Our results are similar to the findings of WILLEMS et al. [21], who showed that small airway disease is related to the destruction of peribronchial alveoli. These findings support the hypothesis that CLE is a secondary phenomenon intimately related to the primary involvement of the airways in some smokers.

We used the point counting method as a qualitative tool to separate the different types of parenchymal destruction, but this method does not quantitate the severity of the disease in a comparable way in the four emphysema groups. Hence, it is not surprising that $\mathrm{FEV}_{1}$ and $\mathrm{PL}_{90}$ are not found to be different among the four groups, especially since most of our cases had mild physiological abnormalities. However, as KIM et al. [4] have shown, compliance is normal or low in the centrilobular type of emphysema and high in the panlobular type of emphysema. Furthermore, compliance increases as Lm increases in PLE but not in CLE [4], suggesting that the two types of parenchymal involvement express themselves differently mechanically. The shape of the pressurevolume curve, as expressed by $\mathrm{K}$, is normal in CLE and tends to become more abnormal, indicating loss of elasticity as PLE involvement increases. These findings suggest that as the parenchymal abnormalities become more diffuse - increased involvement of the lung with PLE - there is a greater loss of elasticity.

In conclusion, smokers develop mainly two types of emphysema, a predominant CLE or PLE emphysema, that can be separated by lung mechanics. However, a mild degree of overlap between the two emphysemas seems to influence the pattern and degree of small airway involvement. These findings suggest that the pathogenesis of lung destruction in smokers is not homogenous and two main mechanisms, one centred around airways - airborne - and another acting differently - blood borne - are involved.

\section{References}

1. Snider GL, Kleinerman J, Thurlbeck WM, Bengali ZH. The definition of emphysema. Report of a National Heart, Lung and Blood Institute, Division of Lung Diseases, Workshop. Am Rev Respir Dis 1985; 132: 182-185.

2. Thurlbeck WM. Chronic airflow obstruction in lung disease. Philadelphia, WB Saunders, 1976.

3. Eidelman DH, Ghezzo H, Kim WD, Hyatt RE, Cosio MG. Pressure-volume curves in smokers. Comparison with alpha $a_{1}$-antitrypsin deficiency. Am Rev Respir Dis 1989; 139: 1452-1458.

4. Kim WD, Eidelman DH, Izquierdo JL, Ghezzo H, Saetta MP, Cosio MG. Centrilobular and panlobular emphysema in smokers. Two distinct morphological and functional entities. Am Rev Respir Dis 1991; 144: 1385-1390.

5. Ferris BG. Epidemiology standardization project. III. Recommended standardized procedures for pulmonary function testing. Am Rev Respir Dis 1978; (Part 2 of 2) 118: $55-88$.

6. Morris JF, Koski WA, Johnson LC. Spirometric standards for healthy nonsmoking adults. Am Rev Respir Dis 1971; 103: 57-67.

7. Goldman HI, Becklake MR. Respiratory function tests: normal values at median altitudes and the prediction of normal results. Am Rev Tuberc 1959; 79: 457-463.

8. Milic-Emili J, Mead J, Turner JM, Glauser EM. Improved technique for estimating pleural pressure from esophageal balloons. J Appl Physiol 1964; 19: 207-211.

9. Saetta M, Shiner RJ, Angus GE, et al. Destructive index: a measurement of lung parenchymal destruction in smokers. Am Rev Respir Dis 1985; 131: 764-769.

10. Colebatch HJH, Ng CKY, Nikov N. Use of an exponential function for elastic recoil. J Appl Physiol: Respirat Environ Exercise Physiol 1979; 46: 387-393.

11. Colebatch HJH, Greaves IA, Ng CKY. Exponential analysis of elastic recoil and aging in healthy males and 
females. J Appl Physiol: Respirat Environ Exercise Physiol 1979; 47: 683-691.

12. Valls AA, Cosio MG. Periodic acid Schiff - haematoxylin, phloxine, saffron: a new multipurpose stain. $J$ Histotechnol 1979; 2: 104-105.

13. Hansen JE, Ampaya EP. Human air space shapes, sizes, areas and volumes. J Appl Physiol 1975; 38: 990-995.

14. Pratt PC, Kilburn KH. A modern concept of the emphysemas based on correlations of structure and function. Hum Pathol 1970; 1: 443-463.

15. Leopold JG, Gough J. The centrilobular form of hypertrophic emphysema and its relation to chronic bronchitis. Thorax 1957; 12: 219-235.

16. Thurlbeck WM. The internal surface areas of nonemphysematous lungs. Am Rev Respir Dis 1967; 95: 765-773.

17. Cosio M, Ghezzo H, Hogg JC, et al. The relations between structural changes in small airways and pulmonary function tests. N Engl J Med 1977; 298: 1277-1281.
18. Cosio MG, Hale KA, Niewoehner DE. Morphologic and morphometric effects of prolonged cigarette smoking on the small airways. Am Rev Respir Dis 1980; 122: 265271.

19. Nagai A, Yamawaki I, Thurlbeck WM, Takizawa T. Assessment of lung parenchymal destruction by using routine histologic tissue sections. Am Rev Respir Dis 1989; 139: 313-319.

20. Orie NGM, Sluiter HJ, de Vries K, Tammeling GJ, Witkop J. The host factor in bronchitis In: Orie NGM, Sluiter HJ, eds. Bronchitis: an international symposium 2729 April 1960: University of Groningen, The Netherlands. Springfield, III, Charles C. Thomas, 1961; pp. 43-59.

21. Willems LNA, Kramps JA, Stijnen T, Sterk PJ, Weening JJ, Dijkman JH. Relation between small airways disease and parenchymal destruction in surgical lung specimens. Thorax 1990; 45: 89-94. 